\title{
HEMIPLEGIA ADQUIRIDA JUVENIL DE ETIOLOGLA DESCONOCIDA
}

\author{
Drs. MARIANO LATORRE Y JESSIE MANHOOD
}

Catedra de Pediatría del Prot. Anibal Ariztia.

Hospital "Luis Calvo Mackenna". Santiago.

La hemiplegia adquirida juvenil o Poliencefalitis de Strümpell es una afección de etiología no precisada, que se presenta de preferencia en el niño menor de seis años. Clínicamente se caracteriza por un comienzo brusco, con estado de coma y convulsiones. Junto con la recuperación de la conciencia se aprecia la aparición de una hemiplegia. En la Anatomía Patológica lo que más sobresale son las lesiones vasculares encefálicas.

Del grupo de Hemiplegias, observadas en el Hospital "Calvo Mackenna" en el período comprendido entre los años 1943 y 1956, como podrá observarse en el Cua. dro N 1; existen seis; cuya gravedad en el período agudo, el carácter casi siempre focal de las crisis, y la posibilidad de emitir un diagnóstico basado en la observación clínica; hacen indispensable un mejor conocimiento de esta enfermedad.

El análisis clínico de estos 6 casos nos hace sintetizar los resultados en un hecho notable: en esta enfermedad el único medio diagnóstico es en realidad la anamnesis.

Es necesario, por lo tanto, conocer con detalle la iniciación y evolución de esta entidad para poder estar razonablemente seguro.

OUADRO NO 1

FIIOLOGIA DE LAS HEMTPLEGIAS

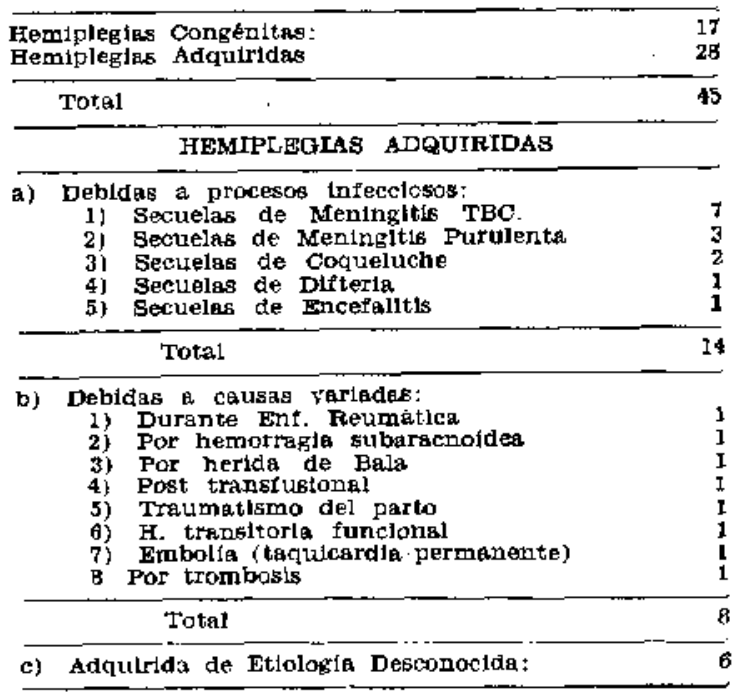

Como en otros cuadros clínicos (Guillain Barre) la literatura está llena de cuadros semejantes que podrían incluirse en este título; pero una vez más es necesario limitarse a las normas clásicas ya que, ni las secuelas, ni la Anatomia Patológica, por escasez, son capaces de asegurar el diagnóstico.

\section{cuadeo clíntco}

Imitando la frase de Ford, la enfermedad se inicia como tormenta en cielo claro. La etapa aguda se caracteriza por convulsiones y coma. Las convulsiones son hemilaterales o veces generalizadas, pueden ser únicas o repetirse en el curso de las primeras 48 horas. El estado comatoso se prolonga por horas a dias al cabo de los cuales el niño recupera paulatinamente la conciencia; sólo en ese momento es evidente aue el enfermo presenta una hemiplegia.

De acuerdo con la localización, existe como signo agregado afasia.

Acompañando este cuadro hay fiebre, vómitos, signos meníngeos discretos. Precisamente el cuadro febril ha hecho siempre difícil la interpretación inicial y asi algunos de nuestros enfermos ingresaron bajo el titulo de Meningitis Tbe., Absceso cerebral, Tumor, etc.

En la fase crónica es evidente que el pequeño presenta una hemiplegia, con $\circ$ sin afasia de acuerdo a la localización. La capacidad intelectual está disminuída y la secuela motora es permanente. Es necesario advertir que este cuadro clinico traduce una lesión encefálica grosera y por lo tanto no es de sorprender que pasado un tiempo variable el $50 \%$ de estos enfermos presente crisis convulsivas de carácter recurrente.

El plazo entre la etapa aguda y estas crísis varía entre semanas y años (hasta 20 años!.

Este tipo de enfermo, cuando sus condiciones clínicas lo indican, es decir imposibilidad de control medicamentoso de las convulsiones, son terreno ideal para la hemisferectomía. 
En cuanto a la parte motora la hemiplegia que se observa al recuperar el conocimiento, es fláccida en un comienzo, posteriormente se hace espástica. Se ha visto que el lado hemiplégico tiene una cierta recuperación de la motilidad, empezando por la musculatura facial, seguida de la extremidad inferior, y por último la superior.

\section{ANATOMÍA PATOLÓGICA}

Los estudios anátomo patológicos son escasos. La mayoría de los autores que se han preocupado de investigar el problema han encontrado lesiones de los vasos arteriales o venosos, del encéfalo.

Así Ford observó un reblandecimiento cerebral por trombosis de la arteria cerebral media. Existían alteraciones de las tres capas de tejido conjuntivo llenas de lipoides; la media y la muscular estaban adelgazadas, y en la capa elástica las láminas en parte se veían engrosadas, y en parte desintegradas. Estas lesiones arteriales también estaban presentes en otras vísceras, pero en un grado más discreto.

Ghetti encontró una hemorragia del ventriculo medio, que comprometía la cápsula interna desde el polo frontal al occipital, existiendo un proceso de endoarteritis difusa de las arterias cerebrales.

En los casos que se han presentado en este trabajo no hay estudio anátomo patológico pues no ha fallecido ninguno.
CASUÍSTICA

a) Distribución por Sexo:

$$
\begin{array}{ll}
4 & \text { niñas } \\
2 & \text { niños }
\end{array}
$$

b) Distribución por edades:

$$
\begin{aligned}
& 1 \text { caso de } 7 \text { meses } \\
& 2 \text { casos de } 1 \text { año } 3 \text { meses } \\
& 1 \text { caso de } 1 \text { año } 6 \text { meses } \\
& 1 \text { " de } 4 \text { años } \\
& 1 \text { " de } 4 \text { años } 10 \text { meses }
\end{aligned}
$$

c) Antecedentes del Parto: en cinco casos el parto fué normal, de término; en el sexto, no se consigna.

\section{d) Antecedentes mórbidos:}

Un caso con antecedentes de Coqueluche, Sarampión, y un proceso TBC.

Un caso con antecedentes de un cuadro febril a los 4 meses de edad que fué seguido de impotencia funcional de las extremidades derechas. A los 6 meses sufrió un Traumatismo encéfalocraneano con pérdida del conocimiento $\mathrm{y}$ bundimiento del cráneo. Sin negar la posibilidad de la influencia del traumatismo al examen clínico no se comprobó hundimiento del cráneo y además las secuelas no son las de un Traumatismo encéfalocraneano propia-

\begin{tabular}{|c|c|c|c|c|c|c|}
\hline $\begin{array}{l}\text { CUADRO } \\
\text { CLINJCO }\end{array}$ & CASO 1 & CASO 2 & CASO 3 & CABO 4 & CASO 5 & CASO 6 \\
\hline AURA & — & - & $\begin{array}{l}\text { E3TADO } \\
\text { ANGUBTIOSO }\end{array}$ & - & — & - \\
\hline CORISI & A IZQUTERDA & SI & A IZQUIERDA & SI & A DERECHA & 8I \\
\hline $\begin{array}{c}\text { NUMURRO } \\
\text { DE CRISIS }\end{array}$ & 3 & $\longrightarrow$ & 2 & 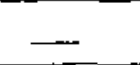 & $\longrightarrow$ & - \\
\hline $\begin{array}{l}\text { PERDIDA DEL } \\
\text { CONOCIMIENTO }\end{array}$ & SI & SI & SI & sI & SI & SI \\
\hline VONITAS & - & SI & $\ldots$ & $\longrightarrow$ & $\longrightarrow$ & - \\
\hline $\begin{array}{l}\text { REIAAJACION } \\
\text { DE ESETINTERES }\end{array}$ & 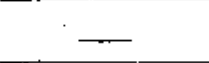 & $\square$ & SI & $\longrightarrow$ & No & - \\
\hline FIFERE & - & $\longrightarrow$ & - & SI & $\longrightarrow$ & - \\
\hline SECDELAS & $\begin{array}{c}\text { HEMIPLEGLA } \\
\text { IZQULERDA }\end{array}$ & $\underset{\text { DERECHA }}{\text { HEMTPLEGLA }}$ & HE IIPLECFA HE & $\begin{array}{l}\text { MIPLEGLA } \\
\text { QUTERDA }\end{array}$ & $\begin{array}{l}\text { HEMLPLEGIA HD } \\
\text { DERECHA Y } \\
\text { AEASIA }\end{array}$ & $\begin{array}{l}\text { IPLEGLA } \\
\text { RECHA Y } \\
\text { ASIA }\end{array}$ \\
\hline
\end{tabular}
mente tales (Hemiplegia derecha espástica).

Un caso con antecedentes de Sarampión. 3 sin antecedentes consignados.

CUAD 20 NO 2

DETALLE DE LOS SINTOMAS CLINICOS EN 6 CASOS

$\varpi$ No conslenado especiflcamente en la historla. 
e) Cuadro Clínico : resumido en el Cuacro $\mathrm{N}^{\circ} 2$.

f) Por el interés que significa el diagnóstico de este cuadro se incluyen los diagnósticos de ingreso:

1.er Caso: Infección TBC. Retardo pondoestatural. Hemiparesia izquierda. Colitis.

$2^{\circ}$ Caso: Secuelas de Polioencefalitis.

3.er Caso: Psoriasis - Convulsiones.

$4^{9}$ Caso: Sarampión - Secuelas de Hemiplegia.

5 ? Caso: Convulsiones - ¿Hemiplegia?¿Tumor?

$6^{\circ}$ Caso: TBC. pulmonar - Meningitis TBC. - Tuberculoma cerebral - Hemiparesia derecha.

g) En lo que a Laboratorio se refiere, a estos enfermos se les practicó:

Electroencéfalograma en todos los casos.

Líquido Céfalo Raquídeo en tres casos.

Radiografía simple de cráneo en tres casos.

Neumoencéfalografía en tres casos.

El estudio electroencéfalográfico en tres casos revela signos en el hemisferio opuesto a la hemiplegia; en dos casos las lesiones son del mismo lado, no tenemos una explicación clara para este fenómeno. En el último caso hay signos en el hemisferio opuesto a la hemiplegia, en el primer examen, y en el segundo practicado 2 años más tarde, se observa que el daño es más intenso en el mismo lado de la Hemiplegia. Probablemente este fenómeno se debe a la extensión del trombo hacia los vasos del hemisferio opuesto.

El líquido céfalo raquídeo se practicó en tres casos; el resultado fué normal. Lo corriente es que el L.C.R. no se altere; se describe un aumento del número de células más o menos a las dos semanas de evolución, hecho que se debería a la reacción meníngea frente al tejido necrótico existente.

La Rađiografía de Cráneo simple en dos casos fué normal, en el tercero existia asimetría del cráneo por abombamiento de la región parietal derecha, (la hemiplegia era izquierda). En el resto de los casos no se practicó.

La Neumoencefalografía se hizo en tres de los casos. En uno fué normal, en un segundo caso con hemiplegia izquierda se apreciaba un aumento de la neumatización a derecha, con discreta tracción de los ventrículos a ese mismo lado. El tercer caso tenía una atrofia cortical izquierda (con una hemiplegia derecha).
Pronóstico: En cuanto a sobrevida es benigna, pero en cuanto a función no es tan favorable.

Tratamiento: En los casos ya vistos sólo se hizo tratamiento sintomático en la fase aguda, en la etapa crónica se administró tratamiento anticonvulsivante.

\section{ETIOLOGÍA}

En cuanto a la etiologia del cuadro, hasta el momento actual no hay una explicación definitiva. Solamente existen teorías que podrían dividirse en etiologías infecciosas, vascular y de causas prenatales y natales.

De naturaleza infecciosa: Strümpell pensó que se trataba de la localización del virus de la Poliomielitis en el tejido cerebral. En contra de esta hipótesis existen dos hechos importantes:-

1) Que en la Polio son excepcionales las parálisis de típo espástico.

2) Inyectando el virus de la Polio intracerebralmente en monos, se observa que el cuadro que se presenta es una parálisis de tipo espinal, y no uno semejante al de la Hemiplegia adquirida juvenil.

Ghetti pensó que la causa era sifilítica basándose en el proceso de endoarteritis en los vasos cerebrales en el caso estudiado por él.

Rothman opina que se trata de una encefalitis localizada no purulenta, sin dar mayores datos que apoyen su posición.

En cuanto a las lesiones vasculares hay opiniones distintas, Gowers cree que se trata de trombosis, Abercrombie de embolías, Sachs dice que las convulsiones producirían secundariamente una hemorragia cerebral. Para Osler serían rupturas de aneurismas congénitos. Mitchell habla de Trombosis venosa, basándose en los hechos siguientes:

a) Que las convuIsiones se propagan, es decir, comienzan en una región $y$ de ahí se generalizan.

b) Que la hemiplegia se recupera parcialmente.

c) Que las trombosis se extienden de un hemisferio al otro, como se vió en un caso observado por él, en que las convulsiones fueron de un solo lado, presentándose a las pocas horas en el lado opuesto.

Por último Wyllie opina que esta afección que se presenta en los primeros años de la vida y que se acompaña de défieit mental, probablemente debe tener causas prenatales y natales. En apoyo de este 
planteamiento existe, según él, casi siempre el antecedente de un trabajo de parto difícil. La anoxia producida por este mecanismo dejaria hemorragias petequiales en el cerebro, o áreas necróticas, que con el tiempo se convertirian en áreas quisticas, llevando así a la atrofia de un hemisferio cerebral.

De todos estos autores, sólo Ford, Ghetti y Mitchell han publicado y hecho estudios anátomo patológicos.

En todo caso, el hecho que se trate de un proceso encefálico, de iniciación brusca, habla en favor de un accidente vascu1ar, pero no hay una explicación clara de cómo se produce, $y$ por qué se produce en épocas determinadas de la infancia. Además, es difícil tener una base etiopatogénica considerando que el estudio anátomo patológico es escaso hasta la fecha.

\section{RESUMEN}

Se analizan las causas más frecuentes de Hemiplegia en el niño. Entre ellas se hace un estudio desde el punto de vista clínico de la Hemiplegia Infantil Adquirida de Etiología Oscura. El trabajo tiene por objeto el análisis de los hechos clinicos que permiten cierta seguridad diagnóstica, especialmente en los que se refiere a anamnesis, los sintomas objetivos y las secuelas.
La observación se basa en seis historias clínicas que se han presentado en un período de diez años. Junto al análisis de los casos se revisa la literatura en lo que respecta a etiologia. Se hace especial mención de las secuelas motoras, afasia, mentalidad infantil y crisis convulsivas.

\section{BIELIOGRAFIA}

1. MENEGGELLO, J., MANTBROLA, A. GRATEROL, O. - Hemlpleglas en la infancta Eesión de la Socledad Chllena de Pediatria del 11-XI-54, publicada en la Revista Chilena de Pedistrib, Año XXVi, No 5, Mayo, 1955 .

2.-AGUAYO, R. - Heraiplegia of Unknown Etiologs in Chllaren. Boletín de la Asociación Medica de Puerto Rico. No 9 , Septlembre de 1944.

3-FORD, F - Diseases of the Nervous Bystem in Infancy Chlldhood and Adolescence. Tercera ediclón. Abrit 1952

4.-FORD, F.. SCHAFFER, A. J, - The Fitiology of Infantile accufred Hemiplegia. Archives of Neurologt and Prychiatry. Vol. 18, io 3 . Septlembre, 1827.

5. GHET'TI, M. - Cerebral Hemorrage in a Chlld. Brithish Medical Journal, Epitome 1, 1910.

6. - IRISF $C . w$ - Cerebra Vascular lesions in New born infants and Young chllaren. Journal or $P \theta-$ diatries. Vol. 15, No 1, Juljo, 1939.

7.-LAITE, FONTAN, DELANDTBHEFR. - Etude d'une série d'Hemipiegles Infantiles. Revue Neurologique. vol. 85: Diciembre, 1951 .

8.-LEVIT, L. - La Hemplegla en log jovenes, Revista Argentina de Neurologia y Psiquatatria. Tomo $v$. No 4, Dlciembre, 1940 .

9.-Mitchell, R. C. - venouts thrombosis in Acute intantile Hemipleg1a. Archives of Dlsenses in Childhood, Vol. 27, NQ 131. Pebrero, 1952.

10.-ROTZMLN, Ph. - Poitoencephaittis, American Jouxngl of Diseases of Children. Yol, 42, No $1, \mathrm{Ju}-$ ilo, 1931 .

11. SPOTA B., BARDACI, C. - Hemiplegra cerebral Infantil NeumaencePalogratia. Revista de Neurolog 19 de Buenos Alres. Vol. XI, N9 3, Septjembre-Diclembre, 1846 .

12.-WILSON. K. W. - Neurologg. Edfclón 1940. (Buttler and Tanner).

13.-WYLIIF, $W, G$. - Acute Infantlle Hemiplegla Proceedings of the Royal Soctety of Medicine. Vol XII, N9 7; Jullo, L948. 